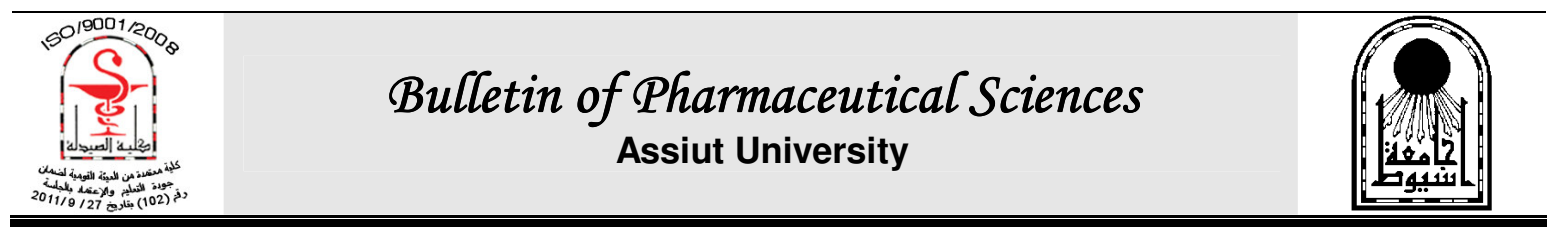

\title{
DESIGN AND SYNTHESIS OF SOME NEW 1,2,4-TRIAZOLE DERIVATIVES AS POTENTIAL ANTIBACTERIAL AGENTS
}

\author{
Alaa M. Hayallah ${ }^{1^{*}}$ and Ibrahim M. Sayed ${ }^{2}$ \\ ${ }^{1}$ Department of Pharmaceutical Organic Chemistry, Faculty of Pharmacy, Assiut University, \\ Assiut 71526, Egypt \\ ${ }^{2}$ Department of Medical Microbiology and Immunology, Faculty of Medicine, Assiut \\ University, Assiut 71526, Egypt
}

\begin{abstract}
Triazoles with different substituent groups are found to possess diverse applications in the field of medicinal chemistry. A new series of novel 1,3,5-trisubstituted[1,2,4]triazole derivatives, their Schiff bases and their amide derivatives were synthesized. Schiff bases (6-10) were prepared by the reaction of the triazoles amine 5 with equimolar amounts of the appropriate substituted benzaldehydes. The amide derivatives (25-39) were obtained by condensation of triazole amines (21-24) with the appropriate acid chloride. Chemical structures were confirmed by IR, ${ }^{1} H-N M R,{ }^{13} C-N M R, F A B-M S$, EI-HRMS spectra and elemental analyses. All the newly synthesized compounds were tested for in vitro activity against certain strains of bacteria such as Staph. aureus, Staph. saprophyticus, Escherichia coli and Bacillus cereus. Most of the tested new compounds exhibited promissing antibacterial activity. Some of them showed antibacterial activity more significant than the reference drugs. Compounds 6-10, 33, 36 and 39 were the most potent derivatives.
\end{abstract}

\section{INTRODUCTION}

The treatment of infectious diseases still remains an important and challenging problem because of factors combination including emerging infectious diseases and the increasing number of multi-drug resistant microbial pathogens. Currently, resistance to first-line antibiotic agents is a severe problem. Infections caused by these resistant microbes fail to respond to treatment resulting in prolonged illness and greater risk of death. The alarming rates of emerging and reemerging microbial threats coupled with increasing antibacterial resistance; particularly in regard to multi drugresistant Gram-positive bacteria are major concerns to the public health as well as scientific communities worldwide ${ }^{1 \& 2}$. These trends have emphasized the pressing need for new, more effective and safe antibacterial agents and which in turn has opened up a new area of research for the scientists ${ }^{1 \& 2}$. In the past years, some azole derivatives were developed as new antimicrobial agents, for instance, Linezolid and Eperezolid are currently used for the treatment of multidrug-resistant Gram positive infections $s^{3-5}$. There are a number of antimicrobial drugs containing a 1,2,4-triazole ring in their structures such as Fluconazole, Itraconazole, Voriconazole, Ravuconazole and Posaconazole that are important antifungal drugs $^{6}$. In addition, Literature survey revealed triazole derivatives which belong to an important group of heterocyclic compounds that have been the subject of extensive study in the recent past. Diverse biological activities, such as antibacterial ${ }^{7-14}$, antifungal ${ }^{8-10 \& 15}$, antiinflammatory $^{16 \& 17}$, anticancer ${ }^{18-21}$, analgesic ${ }^{22}$ and antiviral ${ }^{21}$ have been associated with 1,2,4triazole derivatives.

Moreover, amides as a function group play a key role for medicinal chemists and in depth analysis of the comprehensive medical chemistry data base revealed that the

Received in 23/9/2013 \& Accepted in 19/12/2013 
carboxamide group appears in more than $25 \%$ of known drugs ${ }^{23}$. This can be expected, since carboxamides are neutral, are stable and have both hydrogen-bond accepting and donating properties.

Keeping all the above mentioned facts in view, herein we report the design and synthesis of a novel series of 1,2,4-triazole derivatives linked to amide and Schiff bases as antimicrobial agents.

\section{MATERIAL AND METHODS}

\section{Chemistry}

Reagents used for synthesis were purchased from Sigma-Aldrich and MERCK. All solvents were obtained from commercial suppliers and used without further purification. Melting points were determined on an electrical melting point apparatus (Stuart Scientific, UK), and are uncorrected. Silica gel 60 F254 (Merck) aluminum plates were used for thin layer chromatography. Dichloromethane/methanol $(9: 1 \quad \mathrm{v} / \mathrm{v})$ and cyclohexane/EtOAc $(3: 2 \mathrm{v} / \mathrm{v})$ were used as developing systems and the spots were visualized by ultraviolet light. IR spectra were recorded on a Shimadzu spectrophotometer (IR-470) as potassium bromide discs at the Faculty of Pharmacy, Assiut University. ${ }^{1} \mathrm{H}-$ NMR spectra were performed on Varian EM$360,60 \mathrm{MHz}$ spectrometer at the Faculty of Pharmacy, Assiut University, Egypt. DMSO-d 6 was used as a solvent and the chemical shifts are given in $\delta(\mathrm{ppm})$ values downfield from TMS as internal standard. ${ }^{1} \mathrm{H}-\mathrm{NMR}$ and ${ }^{13} \mathrm{C}$ NMR spectra for amine derivatives and some other compounds were taken using Bruker DPX $300 \mathrm{MHz}$ instrument at Organic Chemistry institute, Bonn, Germany. DMSO- $\mathrm{d}_{6}$ and $\mathrm{CDCl} 3$ were used as solvent and the chemical shifts are given in $\delta(\mathrm{ppm})$ values. The chemical shifts of the remaining protons of the deuterated solvents served as internal standard: $\delta={ }^{1} \mathrm{H}: 2.49 \mathrm{ppm},{ }^{13} \mathrm{C}: 39.7 \mathrm{ppm}$ and $\delta$ ${ }^{1} \mathrm{H}: 7.26$ ppm, ${ }^{13} \mathrm{C}: 77.36 \mathrm{ppm}$ DMSO- $\mathrm{d}_{6}$ and $\mathrm{CDCl} 3$ respectively. The EI-HRMS was obtained using EI- Finnigan MAT 95XL (Thermo Finnigan, Bremen) at Organic Chemistry institute, Bonn, Germany. The EIMS were determined using or JOEL JMS600 mass spectrometer at the Unit of Microanalysis, Assiut University. Elemental microanalyses were performed on a Perkin-Elmer 240 elemental analyzer at the Micro analytical center, Faculty of Science, Cairo University, Egypt. Compounds 2-5, 11a-d, 12 a-d, 13-16, 17-20 and 21-24 were prepared as we reported $^{24}$.

\section{General procedure for synthesis of Schiff} bases (6-10)

To a suspension of 4-(3-methoxy-5(benzo[ $d][1,3]$ dioxol-5-yl)- $1 H-1,2,4-$ triaz-1-yl)phenyl amine (5) $(1.18 \mathrm{mmol})$ in ethanol (15 $\mathrm{mL}$ ), an equimolar amount of the appropriate aldehyde $(1.18 \mathrm{mmol})$ was added. The suspension was gently heated until a clear solution was obtained. Then few drops of glacial acetic acid were added and the solution was refluxed for 7-8 hrs. The reaction mixture was cooled to the ambient temperature and the formed precipitate was filtered and recrystallized from ethanol to yield the target compounds 6-10.

N-(4-Bromobenzylidene)-4-(5-(benzo $[d][1,3]$ dioxol-5-yl)-3-methoxy-1H-1,2,4-triazol-1yl)-benzenamine (6)

${ }^{1} \mathrm{H}-\mathrm{NMR}\left(300 \mathrm{MHz}, \mathrm{DMSO}-\mathrm{d}_{6}\right): \delta: 8.70$ (s, $1 \mathrm{H}, \mathrm{N}=\mathrm{CH}), 7.90(\mathrm{~d}, 2 \mathrm{H}, J=8.46 \mathrm{~Hz}, \operatorname{ArH})$, $7.70(\mathrm{~d}, 2 \mathrm{H}, J=8.46 \mathrm{~Hz}, \mathrm{ArH}), 7.20(\mathrm{~d}, 2 \mathrm{H}, J=$ $8.46 \mathrm{~Hz}, \mathrm{ArH}), 7.10$ (d, 2H, J=8.46 Hz, ArH), 6-90-7.0 (br s, 3H, ArH), 6.00 (s, 2H, $\mathrm{CH}_{2}$, 2H), 3.96 (s, 3H, -O-CH $) .{ }^{13} \mathrm{C}-\mathrm{NMR}(75 \mathrm{MHz}$, DMSO-d ${ }_{6}$ ): $\delta$ 168.03, 161.41, 153.12, 151.63, $149.29, \quad 147.82, \quad 136.19, \quad 135.45, \quad 132.45$, $131.14, \quad 127.08, \quad 125.91, \quad 123.85, \quad 122.50$, 121.58, 109.04, 108.99, 102.29, 57.01. m.p. 144-146, yield 85\%. Anal. Calcd for $\mathrm{C}_{23} \mathrm{H}_{17} \mathrm{BrN}_{4} \mathrm{O}_{3}: \mathrm{C}, 57.88 ; \mathrm{H}, 3.59 ; \mathrm{N}, 11.74$. Found: C, 57.70; H, 3.70; N, 11.92 .

N-(4-Fluorobenzylidene)-4-(5-(benzo $[d][1,3]$ dioxol-5-yl)-3-methoxy-1H-1,2,4-triazol-yl)benzenamine (7)

${ }^{1} \mathrm{H}-\mathrm{NMR}\left(300 \mathrm{MHz}, \mathrm{DMSO}-\mathrm{d}_{6}\right.$ ): $\delta: 8.65$ (s, $1 \mathrm{H}, \mathrm{N}=\mathrm{CH}), 7.90-8.00$ (m, 2H, ArH), 7.257.50 (m, 6H, ArH), 6-90-6.95 (br s, 3H, ArH), $6.00\left(\mathrm{~s}, 2 \mathrm{H}, \mathrm{CH}_{2}\right), 3.95$ (s, $\left.3 \mathrm{H},-\mathrm{O}-\mathrm{CH}_{3}\right) .{ }^{13} \mathrm{C}-$ NMR (75 MHz, DMSO-d d $_{6}$ : $\delta 168.11,163.02$, $161.21, \quad 153.12, \quad 151.86, \quad 149.28, \quad 147.82$, $136.01,133.01, \quad 132.97, \quad 131.80,131.68$, $127.15, \quad 123.85, \quad 122.44, \quad 121.60, \quad 116.64$, 116.36, 109.04, 109.00, 108.99, 102.23, 57.01. Yield 70\%; m.p. 148-150. Anal. Calcd for 
$\mathrm{C}_{23} \mathrm{H}_{17} \mathrm{FN}_{4} \mathrm{O}_{3}$ : C, 66.34; H, 4.11; N, 13.45 .

Found: C, 66.70; H, 4.10; N, 13.80 .

4-(4-(5-(Benzo $[d][1,3]$ dioxol-5-yl)-3methoxy-1H-1,2,4-triazol-1-yl)phenyl-mino)methyl)-phenol (8)

${ }^{1} \mathrm{H}-\mathrm{NMR}\left(300 \mathrm{MHz}\right.$, DMSO-d $\left.\mathrm{d}_{6}\right): \delta: 10.11$ (s, $1 \mathrm{H}, \mathrm{OH}), 8.47(\mathrm{~s}, 1 \mathrm{H}, \mathrm{N}=\mathrm{CH}), 7.76(\mathrm{~d}, 2 \mathrm{H}$, $J=8.46 \mathrm{~Hz}, \operatorname{ArH}), 7.20-7.40(\mathrm{~m}, 4 \mathrm{H}, \operatorname{ArH})$, 6.85-6.91 (m, 5H, ArH), $6.03\left(\mathrm{~s}, 2 \mathrm{H}, \mathrm{CH}_{2}\right)$, $3.91\left(\mathrm{~s}, 3 \mathrm{H},-\mathrm{O}-\mathrm{CH}_{3}\right) .{ }^{13} \mathrm{C}-\mathrm{NMR}(75 \mathrm{MHz}$, DMSO-d $\left.{ }_{6}\right): \delta 168.11,161.67,161.46,153.07$, $152.62, \quad 149.27, \quad 147.82, \quad 135.47,131.43$, $127.79, \quad 127.13, \quad 123.82, \quad 122.27, \quad 121.66$, 116.21, 109.01, 108.98, 56.99. Yield 69\%; m.p. 237-239. Anal. Calcd for $\mathrm{C}_{23} \mathrm{H}_{18} \mathrm{~N}_{4} \mathrm{O}_{4}$ : C, 66.66; H, 4.38; N, 13.52. Found: C, 66.22; H, $4.68 ; \mathrm{N}, 13.25$.

$\mathrm{N}$-(4-Nitrobenzylidene)-4-(5-(benzo $[d][1,3]$ dioxol-5-yl)-3-methoxy-1H-1,2,4-tria-zol1yl)-benzenamine (9)

${ }^{1} \mathrm{H}-\mathrm{NMR}\left(300 \mathrm{MHz}, \mathrm{DMSO}-\mathrm{d}_{6}\right): \delta: 8.83$ $(\mathrm{s}, 1 \mathrm{H}, \mathrm{N}=\mathrm{CH}), 8.35(\mathrm{~d}, 2 \mathrm{H}, J=8.46 \mathrm{~Hz}$, ArH), 8.20 (d, $2 \mathrm{H}, J=8.46 \mathrm{~Hz}, \mathrm{ArH}) 6-40-7.60$ (m, 4H, ArH), 6-90-7.20 (m, 3H, ArH), 6.04 (s, $\left.2 \mathrm{H}, \mathrm{CH}_{2}\right), 3.90\left(\mathrm{~s}, 3 \mathrm{H},-\mathrm{O}-\mathrm{CH}_{3}\right) .{ }^{13} \mathrm{C}-\mathrm{NMR}(75$ MHz, DMSO-d $\left.\mathrm{d}_{6}\right): \delta 168.16,160.75,153.18$, $151.06, \quad 149.51, \quad 149.32, \quad 147.83, \quad 141.74$, $136.71,130.34,127.15,124.55, \quad 123.78$, 122.75, 121.57, 109.07, 109.01, 102.23, 57.03. Yield 80\%; m.p. 192-194. Anal. Calcd for $\mathrm{C}_{23} \mathrm{H}_{17} \mathrm{~N}_{5} \mathrm{O}_{5}$ : C, 62.30; H, 3.86; N, 15.79. Found: C, 62.54; H, 4.18; N, 16.12 .

N-(4-(Dimethylamino)benzylidene)-4-(5(benzo[d][1,3]dioxol-5-yl)-3-methoxy-1H1,2,4-triazol-1-yl)benzenamine (10)

${ }^{1} \mathrm{H}-\mathrm{NMR}\left(300 \mathrm{MHz}, \mathrm{DMSO}-\mathrm{d}_{6}\right): \delta: 8.42$ $(\mathrm{s}, 1 \mathrm{H}, \mathrm{N}=\mathrm{CH}), 7.70(\mathrm{~d}, 2 \mathrm{H}, J=8.46 \mathrm{~Hz}, \mathrm{ArH})$, $7.30(\mathrm{~d}, 2 \mathrm{H}, J=8.46 \mathrm{~Hz}, \operatorname{ArH}) 6-40-7.60(\mathrm{~m}$, 4H, ArH), 6-90-7.20 (m, 3H, ArH), 6.00 (s, 2H, $\left.\mathrm{CH}_{2}\right), 3.90$ (s, 3H, -O-CH $), 2.95(\mathrm{~s}, 6 \mathrm{H}$, $\left.\mathrm{N}\left(\mathrm{CH}_{3}\right)_{2}\right) \cdot{ }^{13} \mathrm{C}-\mathrm{NMR}(75 \mathrm{MHz}$, DMSO-d 6 ): $\delta$ $168.09, \quad 161.53, \quad 153.12, \quad 153.03, \quad 149.24$, $147.81, \quad 135.07, \quad 131.04, \quad 127.12, \quad 124.05$, $123.79, \quad 122.21,121.64,111.96,108.98$, 102.20, 56.98. Yield 65\%; m.p. 190-192. Anal. Calcd for $\mathrm{C}_{25} \mathrm{H}_{23} \mathrm{~N}_{5} \mathrm{O}_{3}: \mathrm{C}, 68.01 ; \mathrm{H}, 5.25 ; \mathrm{N}$, 15.86. Found: C, 67.80; H, 5.30; N, 15.64.
General procedure for synthesis of Amide derivatives (25-39)

To a solution of triazole amine derivative (21-23 or 24) (4.02 mmol, 1 eq.) and triethyl amine $(1.11 \mathrm{ml}, 8.04 \mathrm{mmol}, 2$ eq.) in dry $\mathrm{CH}_{2} \mathrm{Cl}_{2}(20 \mathrm{ml})$ was added appropriate acid chloride (4.02 mmol, 1 eq.). The reaction mixture was stirred overnight at rt. The reaction mixture was diluted with dichloromethane $(100 \mathrm{ml})$. The reaction mixture was washed with $5 \%$ aq. $\mathrm{Na}_{2} \mathrm{CO}_{3}$ solution $(25 \mathrm{ml})$ and water $(2 \times 50 \mathrm{ml})$, respectively. The organic phase was dried over $\mathrm{MgSO}_{4}$, filtered and evaporated to dryness. The crude product was purified by silica gel chromatography using (Cyclohexane:EtOAc, $1: 1 \mathrm{v} / \mathrm{v})$ as eluent or recrystallized from aqueous ethanol to give the target products 2539.

\section{N-(4-(3-Methoxy-5-phenyl-1H-1,2,4-triazol- 1-yl)phenyl)benzamide (25)}

IR $\left(\mathrm{cm}^{-1}\right)$ : v $3345(\mathrm{NH}), 1649(\mathrm{CONH})$, $1591(\mathrm{C}=\mathrm{N}), 1120(\mathrm{C}-\mathrm{O}), 689,710,831(\mathrm{CH})$; ${ }^{1} \mathrm{H}-\mathrm{NMR}\left(60 \mathrm{MHz}, \mathrm{CDCl}_{3}\right): \delta 8.45$ (br s, $1 \mathrm{H}$, Amide NH), 7.70-8.20 (m, 5H, ArH), 7.30-7.60 (m, 9H, ArH), 4.10 (s, 3H, O-CH $\mathrm{CH}_{3}$. Yield 67\%; m.p. 144-46. Anal. Calcd for $\mathrm{C}_{22} \mathrm{H}_{18} \mathrm{~N}_{4} \mathrm{O}_{2}$ : C, 71.34; H, 4.90; N, 15.13. Found: C, 71.24; H, $4.98 ; \mathrm{N}, 15.34$.

\section{4-Chloro-N-(4-(3-Methoxy-5-phenyl-1H- 1,2,4-triazol-1-yl)phenyl)benzamide (26)}

IR $\left(\mathrm{cm}^{-1}\right)$ : v $3350(\mathrm{NH}), 1654(\mathrm{CONH})$, $1590(\mathrm{C}=\mathrm{N}), 1107(\mathrm{C}-\mathrm{O}), 833(\mathrm{CH}) ;{ }^{1} \mathrm{H}-\mathrm{NMR}$ $\left(60 \mathrm{MHz}, \mathrm{CDCl}_{3}\right): \delta 8.35$ (br s, $1 \mathrm{H}$, Amide $\mathrm{NH}), 8.10(\mathrm{~d}, J=8.50 \mathrm{~Hz}, 2 \mathrm{H}, \mathrm{ArH}), 7.20-8.00$ $(\mathrm{m}, 11 \mathrm{H}, \mathrm{ArH}), 4.00\left(\mathrm{~s}, 3 \mathrm{H}, \mathrm{O}-\mathrm{CH}_{3}\right)$. Yield 65\%; m.p. 170-172. Anal. Calcd for $\mathrm{C}_{22} \mathrm{H}_{17} \mathrm{ClN}_{4} \mathrm{O}_{2}$ : C, 65.27; H, 4.23; N, 13.84 . Found: C, 64.90; H, 4.58; N, 13.34. EI MS $(\mathrm{m} / \mathrm{z})$ : $406.19(\mathrm{M}+2,3 \%), 404.04(\mathrm{M}+, 9 \%)$, 312.29, 264.87, 138.91 (100\%), 110.94 .

\section{2-Chloro-N-(4-(3-Methoxy-5-phenyl-1H-}

\section{1,2,4-triazol-1-yl)phenyl)benzamide (27)}

IR $\left(\mathrm{cm}^{-1}\right)$ : v $3330(\mathrm{NH}), 1680(\mathrm{CONH})$, $1535(\mathrm{C}=\mathrm{N}), 1180(\mathrm{C}-\mathrm{O}), 750(\mathrm{CH}) ;{ }^{1} \mathrm{H}-\mathrm{NMR}$ $\left(60 \mathrm{MHz}, \mathrm{CDCl}_{3}\right): \delta 8.60$ (br s, $1 \mathrm{H}$, Amide $\mathrm{NH})$, 8.00-8.20 (m, 4H, ArH), 7.10-7.90 (m, 9H, ArH), 4.10 (s, 3H, O- $\mathrm{CH}_{3}$ ). Yield 69\%; m.p. 163-165. Anal. Calcd for $\mathrm{C}_{22} \mathrm{H}_{17} \mathrm{ClN}_{4} \mathrm{O}_{2}$ : 
C, 65.27; H, 4.23; N, 13.84. Found: C, 64.90; $\mathrm{H}, 4.10 ; \mathrm{N}, 13.28$.

3,5-Difluoro-N-(4-(3-Methoxy-5-phenyl-1H1,2,4-triazol-1-yl)phenyl)benzamide (28) IR $\left(\mathrm{cm}^{-1}\right)$ : v $3325(\mathrm{NH}), 1645(\mathrm{CONH})$, $1586(\mathrm{C}=\mathrm{N}), 1116(\mathrm{C}-\mathrm{O}), 742,693(\mathrm{CH}) ;{ }^{1} \mathrm{H}-$ NMR $\left(60 \mathrm{MHz}, \mathrm{CDCl}_{3}\right): \delta 8.50($ br s, $1 \mathrm{H}$, Amide NH), 8.00-8.25 (m, 5H, ArH), 7.30-7.80 (m, 7H, ArH), 4.10 (s, 3H, O- $\mathrm{CH}_{3}$ ). Yield 75\%; m.p. 157-159. Anal. Calcd for $\mathrm{C}_{22} \mathrm{H}_{16} \mathrm{~F}_{2} \mathrm{~N}_{4} \mathrm{O}_{2}$ : C, 65.02; H, 3.97; N, 13.79. Found: C, 64.66; $\mathrm{H}, 3.68 ; \mathrm{N}, 13.79$.

N-(4-(5-(4-tert-Butylphenyl)-3-methoxy-1H1,2,4-triazol-1-yl)phenyl)benzamide (29)

IR $\left(\mathrm{cm}^{-1}\right)$ : v $3330(\mathrm{NH}), 1675(\mathrm{CONH})$, $1545(\mathrm{C}=\mathrm{N}), 1180(\mathrm{C}-\mathrm{O}), 842,697(\mathrm{CH}) ;{ }^{1} \mathrm{H}-$ NMR $\left(60 \mathrm{MHz}, \mathrm{CDCl}_{3}\right): \delta 8.40($ br s, $1 \mathrm{H}$, Amide NH), 7.70-7.90 (m, 4H, ArH), 7.20-7.60 (m, 9H, ArH), 4.00 (s, 3H, O- $\left.\mathrm{CH}_{3}\right), 1.30$ (s, 9H, $\left.\mathrm{C}\left(\mathrm{CH}_{3}\right)_{3}\right)$. Yield 71\%; m.p. 199-201. Anal. Calcd for $\mathrm{C}_{26} \mathrm{H}_{26} \mathrm{~N}_{4} \mathrm{O}_{2} \cdot \mathrm{H}_{2} \mathrm{O}$ : C, 70.24; $\mathrm{H}, 6.36$; $\mathrm{N}, 12.61$. Found: C, 69.82; H, 6.24; N, 12.25 .

$\mathrm{N}$-(4-(5-(4-tert-Butylphenyl)-3-methoxy-1H1,2,4-triazol-1-yl)phenyl)-4-chlorobenzamide (30)

IR $\left(\mathrm{cm}^{-1}\right)$ : v $3355(\mathrm{NH}), 1674(\mathrm{CONH})$, $1579(\mathrm{C}=\mathrm{N}), 1179(\mathrm{C}-\mathrm{O}), 840(\mathrm{CH}) ;{ }^{1} \mathrm{H}-\mathrm{NMR}$ $\left(60 \mathrm{MHz}, \mathrm{CDCl}_{3}\right): \delta 8.45($ br s, $1 \mathrm{H}$, Amide $\mathrm{NH}), 7.90-8.30(\mathrm{~m}, 5 \mathrm{H}, \mathrm{ArH}), 7.20-7.70(\mathrm{~m}$, $7 \mathrm{H}, \mathrm{ArH}), 4.10\left(\mathrm{~s}, 3 \mathrm{H}, \mathrm{O}-\mathrm{CH}_{3}\right), 1.35(\mathrm{~s}, 9 \mathrm{H}$, $\left.\mathrm{C}\left(\mathrm{CH}_{3}\right)_{3}\right)$. Yield 63\%; m.p. 139-141. Anal. Calcd for $\mathrm{C}_{26} \mathrm{H}_{25} \mathrm{ClN}_{4} \mathrm{O}_{2}: \mathrm{C}, 67.75 ; \mathrm{H}, 5.47 ; \mathrm{N}$, 12.15. Found: C, 67.38; H, 5.80; N, 12.35. EI MS $(\mathrm{m} / \mathrm{z}): 461.98(\mathrm{M}+2,3 \%), 460.26(\mathrm{M}+$ 10\%), 489.47, 138.89 (100\%), 110.90 .

N-(4-(5-(4-tert-Butylphenyl)-3-methoxy- $1 H$ 1,2,4-triazol-1-yl)phenyl)-2-chlorobenzamide (31)

IR $\left(\mathrm{cm}^{-1}\right)$ : v $3330(\mathrm{NH}), 1680(\mathrm{CONH})$, $1535(\mathrm{C}=\mathrm{N}), 1180(\mathrm{C}-\mathrm{O}), 835,750(\mathrm{CH}) ;{ }^{1} \mathrm{H}-$ NMR $\left(60 \mathrm{MHz}, \mathrm{CDCl}_{3}\right): \delta 8.60($ br s, $1 \mathrm{H}$, Amide NH), 8.00-8.20 (m, 4H, ArH), 7.10-7.80 (m, 8H, ArH), 4.10 (s, 3H, O-CH $), 1.30(\mathrm{~s}, 9 \mathrm{H}$, $\left.\mathrm{C}\left(\mathrm{CH}_{3}\right)_{3}\right)$. Yield 64\%; m.p. 144-146. Anal. Calcd for $\mathrm{C}_{26} \mathrm{H}_{25} \mathrm{ClN}_{4} \mathrm{O}_{2}: \mathrm{C}, 67.75 ; \mathrm{H}, 5.47 ; \mathrm{N}$, 12.15. Found: C, 67.45; H, 5.75; N, 12.10.
N-(4-(5-(4-tert-Butylphenyl)-3-methoxy-1H1,2,4-triazol-1-yl)phenyl)-3,5-difluo-

robenzamide (32)

IR $\left(\mathrm{cm}^{-1}\right)$ : v $3340(\mathrm{NH}), 1691(\mathrm{CONH})$, $1586(\mathrm{C}=\mathrm{N}), 1110(\mathrm{C}-\mathrm{O}), 833,758,680(\mathrm{CH})$; ${ }^{1} \mathrm{H}-\mathrm{NMR}\left(60 \mathrm{MHz}, \mathrm{CDCl}_{3}\right): \delta 9.00($ br s, $1 \mathrm{H}$, Amide NH), 7.60-7.90 (m, 4H, ArH), 7.10-7.50 (m, 7H, ArH), 4.10 (s, 3H, O-CH $\left.{ }_{3}\right), 1.35$ (s, 9H, $\left.\mathrm{C}\left(\mathrm{CH}_{3}\right)_{3}\right)$. Yield 70\%; m.p. 146-148. Anal. Calcd for $\mathrm{C}_{26} \mathrm{H}_{24} \mathrm{~F}_{2} \mathrm{~N}_{4} \mathrm{O}_{2}: \mathrm{C}, 67.52 ; \mathrm{H}, 5.23 ; \mathrm{N}$, 12.11. Found: C, 67.90; H, 5.30; N, 12.35 .

N-(4-(5-(4-tert-Butylphenyl)-3-methoxy-1H1,2,4-triazol-1-yl)phenyl)-4-methylbenzamide (33)

IR $\left(\mathrm{cm}^{-1}\right)$ : v $3320(\mathrm{NH}), 1699(\mathrm{CONH})$, $1597(\mathrm{C}=\mathrm{N}), 1179(\mathrm{C}-\mathrm{O}), 834,740(\mathrm{CH}) ;{ }^{1} \mathrm{H}-$ NMR $\left(60 \mathrm{MHz}, \mathrm{CDCl}_{3}\right): \delta 8.60($ br s, $1 \mathrm{H}$, Amide NH), 7.80-8.30 (m, 5H, ArH), 7.10-7.60 (m, 7H, ArH), 4.10 (s, 3H, O-CH $\left.{ }_{3}\right), 2.50(\mathrm{~s}, 3 \mathrm{H}$, $\left.\mathrm{CH}_{3}\right), 1.35$ (s, 9H, $\mathrm{C}\left(\mathrm{CH}_{3}\right)_{3}$ ). Yield 67\%; m.p. 148-150. Anal.Calcd for $\mathrm{C}_{27} \mathrm{H}_{28} \mathrm{~N}_{4} \mathrm{O}_{2}$ : C, 73.61; H, 6.41; N, 12.72. Found: C, 73.50; H, 6.64; N, 12.35 .

4-Chloro-N-(4-(3-ethoxy-5-(2,5-difluophenyl)-1H-1,2,4-triazol-1-yl)phenyl)benzamide (34)

IR $\left(\mathrm{cm}^{-1}\right)$ : v $3355(\mathrm{NH}), 1688(\mathrm{CONH})$, $1586(\mathrm{C}=\mathrm{N}), 1188(\mathrm{C}-\mathrm{O}), 833,762,689(\mathrm{CH})$; ${ }^{1} \mathrm{H}-\mathrm{NMR}\left(60 \mathrm{MHz}, \mathrm{CDCl}_{3}\right): \delta 8.50($ br s, $1 \mathrm{H}$, Amide NH), 8.00-8.30 (m, 3H, ArH), 7.10-7.90 $(\mathrm{m}, 8 \mathrm{H}, \mathrm{ArH}), 4.40(\mathrm{q}, J=7.40 \mathrm{~Hz}, 2 \mathrm{H}, \mathrm{O}-$ $\mathrm{CH} 2), 1.50\left(\mathrm{t}, J=7.40 \mathrm{~Hz}, 3 \mathrm{H}, \mathrm{CH}_{3}\right)$. Yield 72\%; m.p. 165-167. Anal. Calcd for $\mathrm{C}_{23} \mathrm{H}_{17} \mathrm{ClF}_{2} \mathrm{~N}_{4} \mathrm{O}_{2}$ : C, 60.73; H, 3.77; N, 12.32 . Found: C, 60.93; H, 3.57; N, 12.55 .

\section{N-(4-(3-Ethoxy-5-(5-(2,5-difluophenyl)- $1 \mathrm{H}$ - 1,2,4-triazol-1-yl)phenyl)-3,5-difluo- robenzamide (35)}

IR $\left(\mathrm{cm}^{-1}\right)$ : v $3275(\mathrm{NH}), 1686(\mathrm{CONH})$, $1592(\mathrm{C}=\mathrm{N}), 1188(\mathrm{C}-\mathrm{O}), 744,684(\mathrm{CH}) ;{ }^{1} \mathrm{H}-$ NMR $\left(60 \mathrm{MHz}, \mathrm{CDCl}_{3}\right): \delta 8.80($ br s, $1 \mathrm{H}$, Amide NH), 7.60-7.80 (m, 4H, ArH), 6.90-7.50 $(\mathrm{m}, 6 \mathrm{H}, \operatorname{ArH}), 4.50(\mathrm{q}, J=7.40 \mathrm{~Hz}, 2 \mathrm{H}, \mathrm{O}-$ $\mathrm{CH}_{2}$ ), $1.50\left(\mathrm{t}, J=7.40 \mathrm{~Hz}, 3 \mathrm{H}, \mathrm{CH}_{3}\right.$ ). Yield 71\%; m.p. 170-172. Anal. Calcd for $\mathrm{C}_{23} \mathrm{H}_{16} \mathrm{~F}_{4} \mathrm{~N}_{4} \mathrm{O}_{2}: \mathrm{C}, 60.53 ; \mathrm{H}, 3.53 ; \mathrm{N}, 12.28$. Found: C, 60.18; H, 3.40; N, 12.24. 
4-Chloro-N-(4-(5-(3-fluorophenyl)-3methoxy-1H-1,2,4-triazol-1-yl)phenyl)benzamide (36)

IR $\left(\mathrm{cm}^{-1}\right)$ : v $3290(\mathrm{NH}), 1680(\mathrm{CONH})$, $1590(\mathrm{C}=\mathrm{N}), 1195(\mathrm{C}-\mathrm{O}), 744,684,835(\mathrm{CH})$; ${ }^{1} \mathrm{H}-\mathrm{NMR}\left(60 \mathrm{MHz}, \mathrm{CDCl}_{3}\right): \delta 8.70($ br s, $1 \mathrm{H}$, Amide NH), 7.90-8.20 (m, 4H, ArH), 7.20-7.80 (m, 8H, ArH), 4.10 (s, 3H, O-CH ${ }_{3}$ ). Yield 72\%; m.p. 165-167. Anal. Calcd for $\mathrm{C}_{22} \mathrm{H}_{16} \mathrm{ClFN}_{4} \mathrm{O}_{2}$ : C, 62.49; H, 3.81; N, 13.25. Found: C, 62.93; $\mathrm{H}, 3.58 ; \mathrm{N}, 13.55$.

N-(4-(3-Methoxy-5-phenyl-1H-1,2,4-triazol1-yl)phenyl)acetamide (37)

IR $\left(\mathrm{cm}^{-1}\right):$ v $3330(\mathrm{NH}), 1660(\mathrm{CONH})$, $1590(\mathrm{C}=\mathrm{N}), 1179(\mathrm{C}-\mathrm{O}), 840(\mathrm{CH}) ;{ }^{1} \mathrm{H}-\mathrm{NMR}$ $\left(60 \mathrm{MHz}, \mathrm{CDCl}_{3}\right): \delta 8.90$ (br s, $1 \mathrm{H}$, Amide $\mathrm{NH}), 7.20-7.90(\mathrm{~m}, 9 \mathrm{H}, \mathrm{ArH}), 4.20(\mathrm{~s}, 3 \mathrm{H}, \mathrm{O}-$ $\mathrm{CH}_{3}$ ), 2.30 (s, $3 \mathrm{H}, \mathrm{CH}_{3}$ ). Yield 60\%; m.p. 152154. Anal. Calcd for $\mathrm{C}_{17} \mathrm{H}_{16} \mathrm{~N}_{4} \mathrm{O}_{2}: \mathrm{C}, 66.22 ; \mathrm{H}$, 5.23; N, 18.17. Found: C, 65.90; H, 5.58; N, 17.80 .

N-(4-(5-(4-tert-Butylphenyl)-3-methoxy-1H1,2,4-triazol-1-yl)phenyl)acetamide (38) IR $\left(\mathrm{cm}^{-1}\right)$ : v $3325(\mathrm{NH}), 1666(\mathrm{CONH})$, $1597(\mathrm{C}=\mathrm{N}), 1179(\mathrm{C}-\mathrm{O}), 841(\mathrm{CH}) ;{ }^{1} \mathrm{H}-\mathrm{NMR}$ $\left(60 \mathrm{MHz}, \mathrm{CDCl}_{3}\right): \delta 8.80$ (br s, $1 \mathrm{H}$, Amide $\mathrm{NH}), 7.90$ (d, $J=8.50 \mathrm{~Hz}, 2 \mathrm{H}, \mathrm{ArH}), 7.20-7.80$ (m, 6H, ArH), 4.25 (s, 3H, O-CH $\left.{ }_{3}\right), 2.40(\mathrm{~s}, 3 \mathrm{H}$, $\left.\mathrm{CH}_{3}\right), 1.35$ (s, 9H, $\left.\mathrm{C}\left(\mathrm{CH}_{3}\right)_{3}\right)$. Yield 62\%; m.p. 145-147. Anal. Calcd for $\mathrm{C}_{21} \mathrm{H}_{24} \mathrm{~N}_{4} \mathrm{O}_{2} \cdot \mathrm{H}_{2} \mathrm{O}$ : C, 65.94; H, 6.87; N, 14.65. Found: C, 65.77; H, $6.92 ; \mathrm{N}, 14.43$.

4-(5-(4-tert-Butylphenyl)-3-methoxy-1H1,2,4-triazol-1-yl)-N-tosylbenzamine (39)

IR $\left(\mathrm{cm}^{-1}\right)$ : v $3325(\mathrm{NH}), 1357,1180(\mathrm{SO} 2-$ $\mathrm{NH}), 1586(\mathrm{C}=\mathrm{N}), 1111(\mathrm{C}-\mathrm{O}), 832,623(\mathrm{CH})$; ${ }^{1} \mathrm{H}-\mathrm{NMR}\left(60 \mathrm{MHz}, \mathrm{CDCl}_{3}\right): \delta 8.50($ br s, $1 \mathrm{H}$, Amide NH), 7.80 (d, $J=8.50 \mathrm{~Hz}, 2 \mathrm{H}, \mathrm{ArH})$, 7.00-7.60 (m, 10H, ArH), 4.10 (s, 3H, O-CH3), $2.50\left(\mathrm{~s}, 3 \mathrm{H}, \mathrm{CH}_{3}\right), 1.30\left(\mathrm{~s}, 9 \mathrm{H}, \mathrm{C}\left(\mathrm{CH}_{3}\right)_{3}\right)$. Yield 70\%; m.p. 128-130. Anal. Calcd for $\mathrm{C}_{26} \mathrm{H}_{28} \mathrm{~N}_{4} \mathrm{O}_{3}$ S.0.5 $\mathrm{H}_{2} \mathrm{O}: \mathrm{C}, 64.30 ; \mathrm{H}, 6.24 ; \mathrm{N}$, 11.54. Found: C, 63.92; H, 6.49; N, 11.20.

\section{Antibacetrial screening}

The antibacterial activity of the entire target compounds 6-10 and 25-39 was investigated in-vitro at the department of microbiology and immunology, faculty of medicine, Assiut University. The title compounds were tested against Staph. aureus (gram positive cocci), Staph. saprophyticus (gram positive cocci), Escherichia coli (gram negative bacilli), and Bacillus cereus(gram positive bacilli), (clinical isolates obtained from Infection Control Unit, Assiut Univeristy Hospital, Faculty of Medicine, Assiut University) using agar cup diffusion method ${ }^{25}$ for susceptibility screening, and two-fold dilution method ${ }^{26}$ for MIC determination. Ampicillin and Garamycin were used as reference antibiotics, and DMSO was used as a solvent control.

\section{Agar cup diffusion method}

$38 \mathrm{~g}$ of Mueller-Hinton agar medium (MH) (Hi-Media, M 001) were added to $1 \mathrm{~L}$ of distilled water, heated to boiling to dissolve the ingredients completely, and sterilized by autoclaving at $121^{\circ} \mathrm{C}$ for 30 minutes. High density inocula were made by diluting 3-5 well isolated colonies grown overnight on selective media in $5 \mathrm{~mL}$ of distilled water to prepare a suspension equivalent in density to 0.5 McFarland Barium Sulfate standard unit with

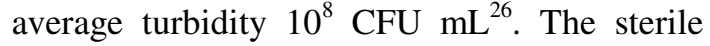
petri dishes were seeded with $100 \mu \mathrm{L}$ of the microorganism; a specified amount of the molten $\mathrm{MH}$ agar medium $\left(45-50^{\circ} \mathrm{C}\right)$ was poured into the seeded Petri dishes togive a depth of 3$4 \mathrm{~mm}$ and allowed to solidify. Cylindrical plugs were removed from the agar using sterile cork borer. $100 \mu \mathrm{L}$ of the tested compounds (20 $\mathrm{mg} / \mathrm{mL}$ in DMSO), the blank solvent, ampicillin sodium and garamycin $(20 \mathrm{mg} / \mathrm{mL}$ in DMSO) were added to the wells in triplicate. The seeded plates were incubated at $37^{\circ} \mathrm{C}$ for $24 \mathrm{hrs}$ then the average diameters of the inhibition zones were measured in millimeters.

\section{Minimum inhibitory concentration}

The MIC values were determined using two fold-dilution method ${ }^{27}$ for compounds having moderate to strong antibacterial activity. The squares of inhibition zone diameters were plotted against log concentrations of the tested compounds, extrapolation of the resulting straight line to intersect with $\log$ concentration scale in the curve corresponded to $\log$ MIC, and MIC was obtained as antilog ${ }^{28}$. 


\section{RESULTS AND DISCUSSION}

\section{Chemistry}

The key intermediate triazole amine derivatives (5, 21-24) were synthesized as shown in schemes $1 \& 2$ starting with benzo[1,3] dioxole-5-carbonyl-chloride or different benzoyl chloride derivatives and potassiumisothiocyanate (KNCS). The 1,2,4-triazol ring was readily assembled from benzo[1,3]dioxole5-carbonyl-isothiocyanate or benzoylisothiocyanate in two steps, using (4-nithrophenyl) hydrazine and then further reduced to afford triazole amine derivatives. These derivatives were confirmed using ${ }^{1} \mathrm{H}-\mathrm{NMR},{ }^{13} \mathrm{C}-\mathrm{NMR}$, FAB-MS, EI-MS and HRMS ${ }^{24}$.

Schiff bases of 1,3,5-trisubstituted [1,2,4] triazole (6-10) were prepared by the reaction of 4-(3-methoxy-5-(benzo[d][1,3]dioxol-5-yl)- $1 H$ 1,2,4-triaz-1-yl)phenyl amine (5) with equimolar amounts of the appropriate substituted benzaldehydes in ethanol in presence of few drops of glacial acetic acid (Scheme 1).

Comparative study of the ${ }^{1} \mathrm{H}-\mathrm{NMR}$ of aminotriazole derivative (5) its Schiff bases (610) easily revealed the disappearance of the $\mathrm{NH}_{2}$ group signal and appearance of $\mathrm{N}=\mathrm{CH}$ signals at $8.40-8.83 \mathrm{ppm}$ in addition to the introduced aromatic moiety. As these findings were observed in the 1HNMR spectra of Schiff bases, it can safely conclude the formation of compounds 6-10 on expense of the $\mathrm{NH}_{2}$. The structures of formed Schiff bases were also further confirmed by ${ }^{13} \mathrm{C}-\mathrm{NMR}$ and elemental analyses (see exp. part).

The final amide compounds 25-39 were synthesized by condensation of amine derivatives (21-24) with the respected acid chloride in dichloromethane and triethylamine as catalyst as illustrated in scheme 2 . The reaction progression was followed by using TLC monitoring; all the synthesized compounds were purified using silica gel chromatography column and/or recrystallized from aqueous ethanol. These new derivatives were verified by IR, ${ }^{1} \mathrm{H}-\mathrm{NMR}$ and elemental analyses. ${ }^{1} \mathrm{H}-\mathrm{NMR}$ spectra of these derivatives were characterized by disappearance of the signal corresponding to $\mathrm{NH}_{2}$ and appearance of downfield signal $(1 \mathrm{H})$ around $\delta 8.35-8.90 \mathrm{ppm}$ corresponding to amidic $\mathrm{NH}$ and signals corresponding to introduced moiety. For example compound 29: IR spectrum showed $(\mathrm{NH}), 1675(\mathrm{CONH}), 1545(\mathrm{C}=\mathrm{N}), 1180(\mathrm{C}-\mathrm{O})$, 842, $697(\mathrm{CH})$ and its ${ }^{1} \mathrm{H}-\mathrm{NMR}$ characterized by signals at $\delta 8.40$ (br s, $1 \mathrm{H}$, amide $\mathrm{NH}$ ), 7.70$7.90(\mathrm{~m}, 4 \mathrm{H}, \mathrm{ArH}), 7.20-7.60(\mathrm{~m}, 9 \mathrm{H}, \mathrm{ArH})$, $4.00\left(\mathrm{~s}, 3 \mathrm{H}, \mathrm{O}-\mathrm{CH}_{3}\right), 1.30\left(\mathrm{~s}, 9 \mathrm{H}, \mathrm{C}\left(\mathrm{CH}_{3}\right)_{3}\right)$.

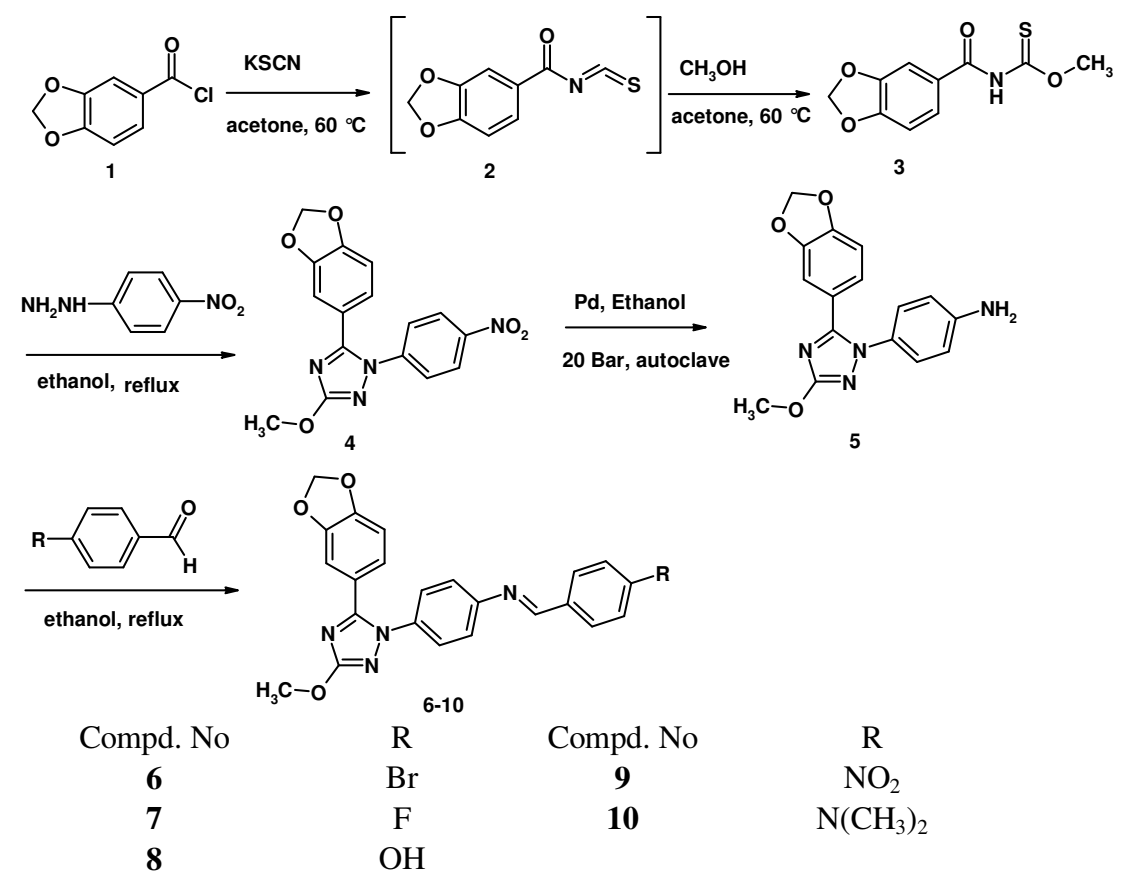

Scheme 1: Synthetic route of 1,2,4-triazole Schiff bases (6-10). 


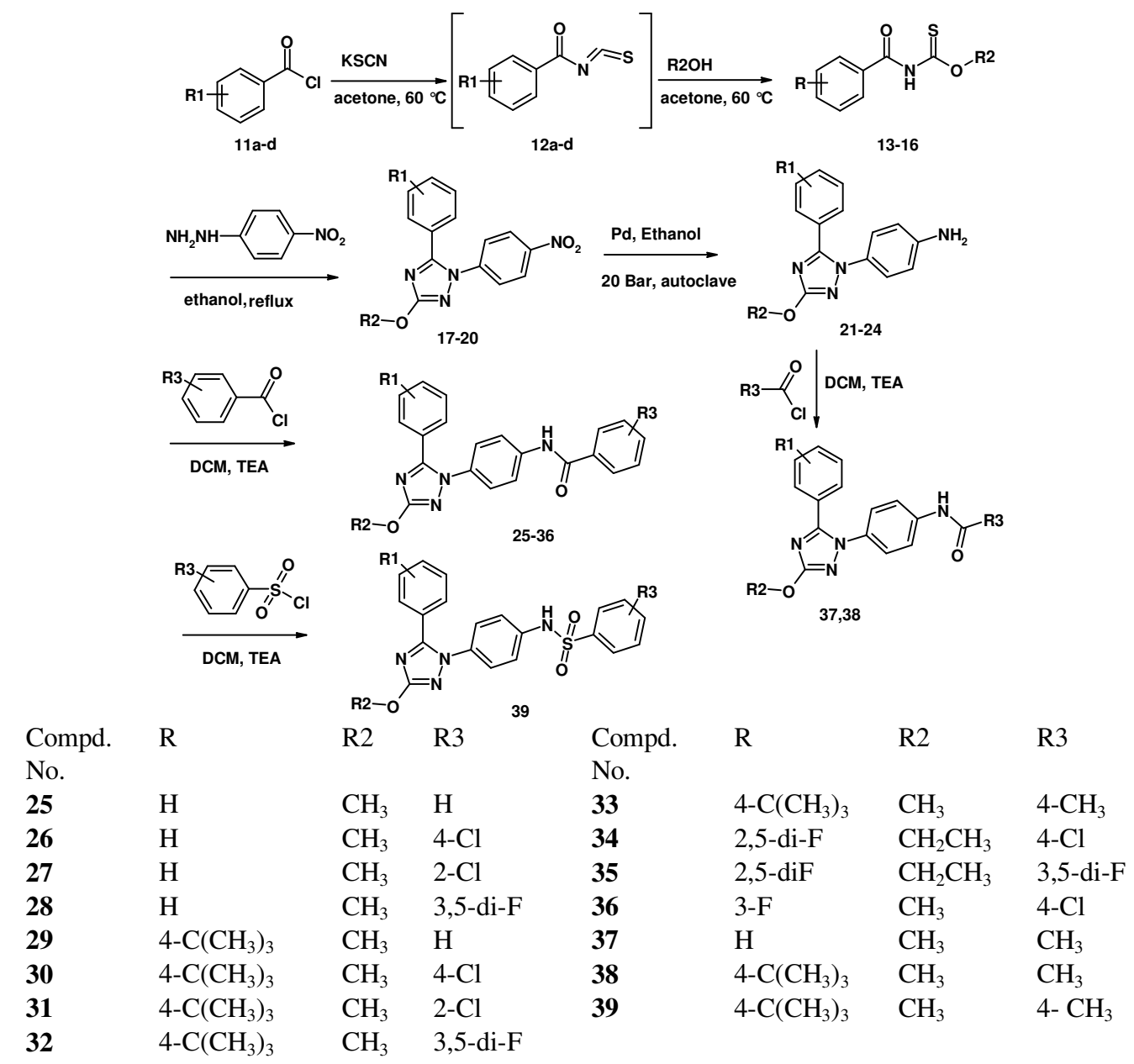

Scheme 2: Synthetic route of the final compounds 25-39.

Compunds 26 and $\mathbf{3 0}$ were further confirmed by EI-MS, they showed 406.19 $(\mathrm{M}+2,3 \%), 404.04(\mathrm{M}+, 9 \%), 312.29,264.87$, $138.91(100 \%), 110.94$ and $461.98(\mathrm{M}+2,3 \%)$, $460.26(\mathrm{M}+, 10 \%), 489.47,138.89$ (100\%), 110.90 respectively.

\section{Antibacterial activity}

The newly synthesized compounds 6-10 and 25-39 were tested for their in vitro antibacterial activity against Staph. aureus, Staph. saprophyticus, Escherichia coli and Bacillus cereus as representatives of Grampositive strains and representatives of Gramnegative ones using ampicillin and garamycin as reference drugs. The results revealed that most of the newly synthesized compounds exhibited promising antibacterial activity against all the test organisms (Figs. 1\&2 and Table 1). Thus Schiff bases compounds 6-10 showed highly significant activity against all tested strains. Their antibacterial activity was higher than ampicillin and comparable with that of garamycin (Fig. 1 and Table 1). Among the synthesized Schiff bases, compound $\mathbf{1 0}$ was the most potent one against all strains, it showed MIC (3.6-3.75 $\mu \mathrm{M})$. Its antibacterial potency was superior to that of ampicillin against all strains. Compound $\mathbf{8}$ was potent against both Staph. saprophyticus and Bacillus cereus, it showed MIC 3.8 and $3.6 \mu \mathrm{M}$ respectively.

Most of the amide compounds 25-39 showed good to very good antibacterial activity (Fig. 2 \& Table 1). Compounds 33, 36 and $\mathbf{3 9}$ exhibited highly pronounced activity against all strains, they showed MIC values 3.75- 8.0 $\mu \mathrm{M} / \mathrm{ml}$. Moreover, compounds 29-32, 35 and 37 showed antibacterial activity higher than ampicillin as reference drug against most 
bacterial strains. Some derivatives 25-28 were comparable to ampicillin activity but compound 25 was inactive against Staph. Saprophyticus. On the other hand, compound 34 was inactive against all strain except Staph aureus and compound $\mathbf{3 8}$ exhibited marked activity against $B$. cereus. Generally, screening results revealed that in most cases, conversion of the amino derivatives to amide derivatives led to better antibacterial activity if compared to activity of amine derivatives (21-24). It seems that the derivatives carrying 4tert.butylphenyl at 5-position of triazole moiety were higher active than that of nonsubstituted phenyl at the same position regardless susbstituents of 1-phenyl moiety. Also, it has been observed that acetyl amide derivative (37) showed analogous activity to that of benzoyl amide derivatives (25) in case of 5-substituted phenyl while $\mathbf{3 8}$ was less active compared to $\mathbf{2 9}$ in which 4tert.butylphenyl at 5-position of triazole moiety instead of phenyl.

Also, it has been observed that introduction of electron withdrawing groups into 1-phenyl substituent produced highly active compounds $\mathbf{3 5}$ and $\mathbf{3 6}$.

In general anticipation of SAR cannot exactly be attained but it seems that the pipronyloyl moiety as substituent is important for the antibacterial activity and this also clear from the activity of key pipronyloyl triazole amine (5) was more active than other amines 21-24 against all bacterial strains. Also, substituted phenyl at position 5 is better than non substituted one.

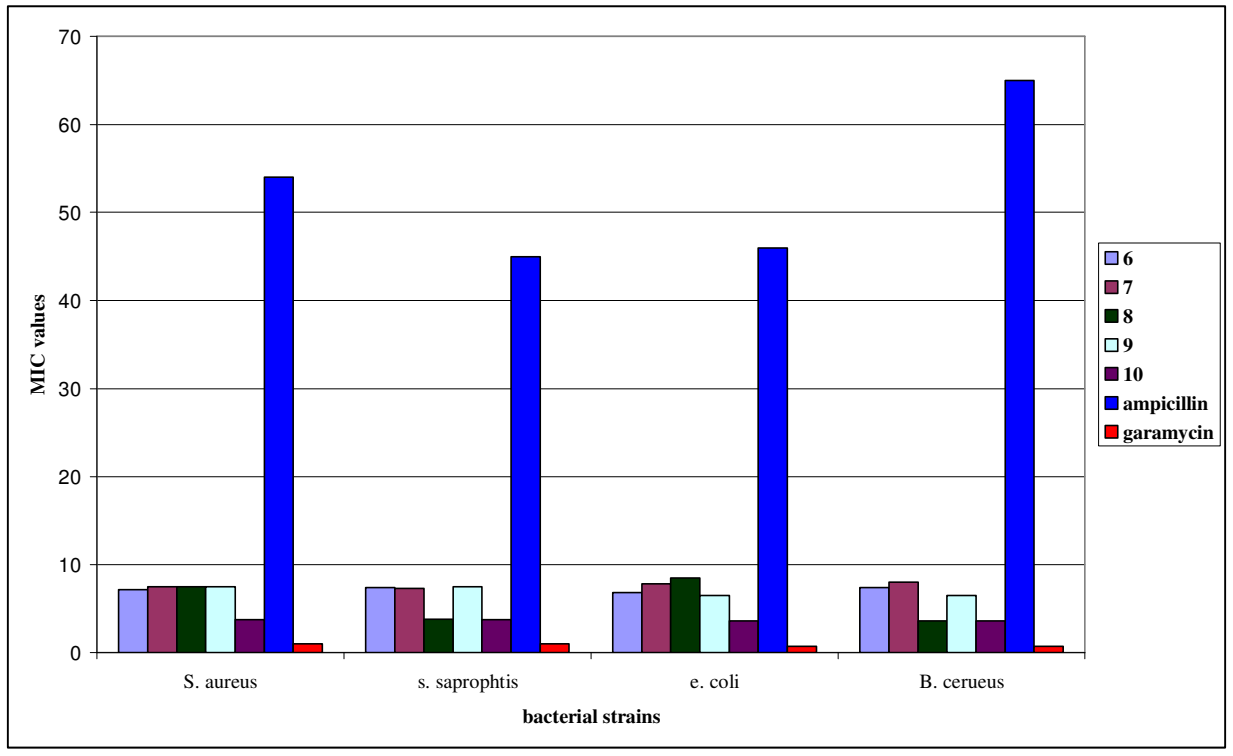

Fig. 1: Comparison of antibacterial activity (MIC, $\mu \mathrm{M} / \mathrm{ml}$ ) of Schiff bases 6-10 with ampicillin and garamycin. 


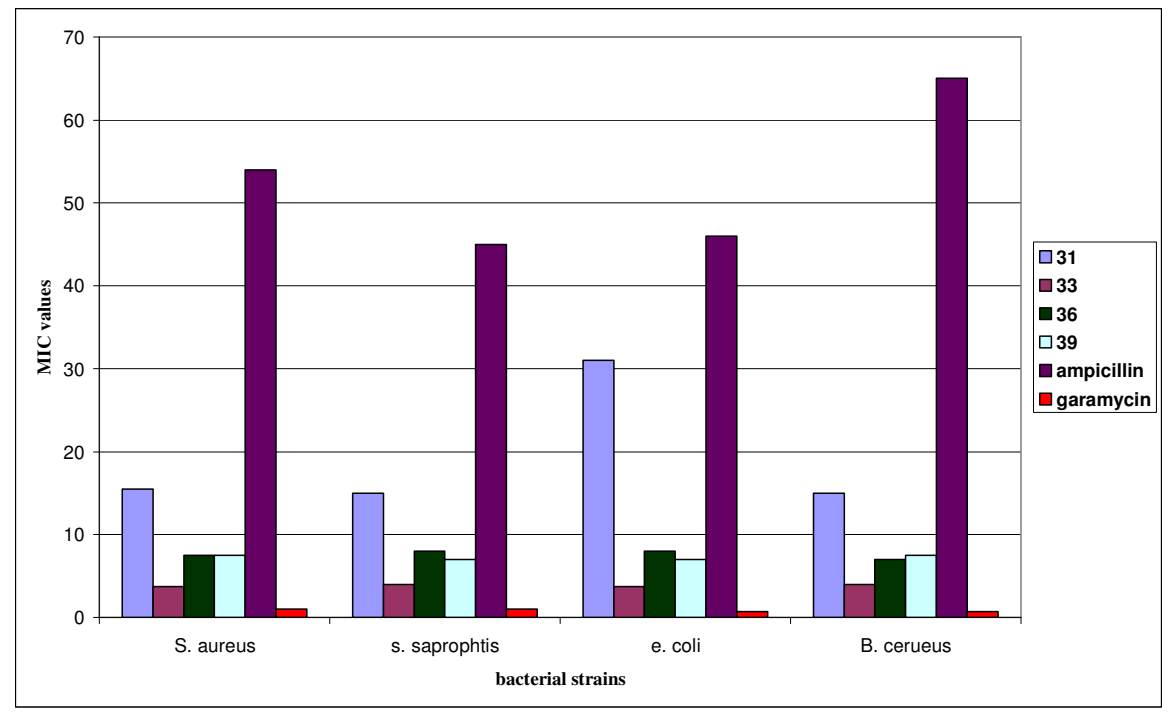

Fig. 2: Comparison of antibacterial activity (MIC, $\mu \mathrm{M} / \mathrm{ml})$ of seleted amide derivatives $(\mathbf{3 1}, \mathbf{3 3}, \mathbf{3 6}$ and 39) with ampicillin and garamycin.

Table 1: Antibacterial activity of the tested compounds (expressed as the inhibition zone diameter and as MIC $\mu \mathrm{M} / \mathrm{mL}$ ).

\begin{tabular}{|c|c|c|c|c|c|c|c|c|}
\hline \multirow[b]{2}{*}{ Compd. No. } & \multicolumn{2}{|c|}{ Staph. aureus } & \multicolumn{2}{|c|}{ Staph. saprophties } & \multicolumn{2}{|c|}{ E. Coli } & \multicolumn{2}{|c|}{ Bacillus cereus } \\
\hline & $\begin{array}{l}\text { Inhibition } \\
\text { zone (mm) }\end{array}$ & $\begin{array}{c}\text { MIC } \\
\mu \mathrm{M} / \mathrm{ml}\end{array}$ & $\begin{array}{l}\text { Inhibition } \\
\text { zone (mm) }\end{array}$ & $\begin{array}{c}\mathrm{MIC} \\
\mu \mathrm{M} / \mathrm{ml}\end{array}$ & $\begin{array}{l}\text { Inhibition } \\
\text { zone (mm) }\end{array}$ & $\begin{array}{c}\mathrm{MIC} \\
\mu \mathrm{M} / \mathrm{ml}\end{array}$ & $\begin{array}{l}\text { Inhibition } \\
\text { zone(mm) }\end{array}$ & $\begin{array}{c}\text { MIC } \\
\mu \mathrm{M} / \mathrm{ml}\end{array}$ \\
\hline 5 & 26 & 31 & 25 & 28 & 28 & 20 & 27 & 21 \\
\hline 6 & 30 & 7.2 & 31 & 7.4 & 30 & 6.8 & 31 & 7.4 \\
\hline 7 & 30 & 7.5 & 30 & 7.3 & 31 & 7.8 & 31 & 8.0 \\
\hline 8 & 30 & 7.5 & 30.5 & 3.8 & 30 & 8.5 & 30.5 & 3.6 \\
\hline 9 & 31 & 7.5 & 30 & 7.5 & 30 & 6.5 & 30 & 6.5 \\
\hline 10 & 30.5 & 3.75 & 31 & 3.75 & 30.5 & 3.6 & 30.5 & 3.6 \\
\hline 21 & 26 & 31 & 10 & 250 & 28 & 20 & 28 & 22 \\
\hline 22 & 27 & 28 & 11 & 125 & --- & $\mathrm{R}$ & 19 & 60 \\
\hline 23 & 10 & 125 & 22 & 64 & --- & 250 & --- & 500 \\
\hline 24 & 11 & 130 & 20 & 70 & --- & 220 & --- & 400 \\
\hline 25 & 21 & 62.5 & --- & $\mathrm{R}$ & 11 & 125 & 26 & 31.5 \\
\hline 26 & 20 & 62.5 & 21 & 62.5 & 21 & 62.5 & 21 & 62.5 \\
\hline 27 & 21 & 62.5 & 26 & 315 & 26 & 30.5 & 25 & 30.5 \\
\hline 28 & 26 & 31.5 & 21 & 62.5 & 21 & 62 & 26 & 30 \\
\hline 29 & 25.5 & 31 & 29 & 15 & 20.5 & 62 & 26 & 31.5 \\
\hline 30 & 26 & 31 & 26 & 31 & 29 & 15.5 & 25 & 31 \\
\hline 31 & 29 & 15.5 & 29 & 15 & 25 & 31 & 30 & 15 \\
\hline 32 & 26 & 31 & 29 & 15 & 25 & 30 & 29 & 15 \\
\hline 33 & 31 & 3.75 & 30.5 & 4.0 & 31 & 3.75 & 30.5 & 4.0 \\
\hline 34 & 27 & 31.5 & --- & $\mathrm{R}$ & --- & $\mathrm{R}$ & --- & $\mathrm{R}$ \\
\hline 35 & 29 & 14 & 29 & 15 & 30 & 12 & 29 & 12 \\
\hline 36 & 30 & 7.5 & 30.5 & 8.0 & 31 & 8.0 & 30 & 7.0 \\
\hline 37 & 21 & 62.4 & 20.5 & 31 & 21 & 31 & 29 & 15 \\
\hline 38 & 21 & 62.4 & 30 & 62 & 30 & 62 & 30 & 15 \\
\hline 39 & 30 & 7.5 & 30 & 7.0 & 30.5 & 7.0 & 31 & 7.5 \\
\hline Ampicillin & 14 & 54 & 13 & 45 & 13 & 46 & 11 & 65 \\
\hline Garamycin & 31 & 1.0 & 30 & 1.0 & 31.5 & 0.75 & 31.5 & 0.75 \\
\hline
\end{tabular}




\section{Conclusions}

Rational design, synthesis of novel series of novel 1,3,5-trisubstituted[1,2,4]triazole derivatives, their Schiff bases and their amide derivatives were synthesized. Schiff bases (610) were prepared by the reaction of the triazoles amine (5) with equimolar amounts of the appropriate substituted benzaldehydes. The amide derivatives (25-39) were obtained by the reaction of triazole amines (21-24) with the appropriate acid chloride. Chemical structures were confirmed by IR, ${ }^{1} \mathrm{H}-\mathrm{NMR},{ }^{13} \mathrm{C}-\mathrm{NMR}$, FAB-MS, EI-HRMS spectra and elemental analyses. All the newly synthesized compounds were tested for in vitro activity against certain strains of bacteria such as Staph. aureus, Staph. saprophyticus, Escherichia coli and Bacillus cereus. Most of them showed antibacterial activity more significant than ampicillin as reference drugs. Also, potent antibacterial compounds were identified such as compounds 6-10, 33, 36 and 39.

\section{Acknowledgment}

We grateful to Prof. Dr. M. Famulok Director of LIMES Institute, Chemical Biology \& Medicinal Chemistry Unit, University of Bonn, Germany for providing some NMR and Mass spectral data of key triazole amine derivatives and his kind collaboration in this project.

\section{REFERENCES}

1- H. Goossens, "European status of resistance in nosocomial infections", Chemotherapy, 51, 177-181 (2005).

2- D. Styers, D. J. Sheehan, P. Hogan and D. F. Sahm, "Laboratory-based surveillance of current antimicrobial resistance patterns and trends among Staphylococcus aureus: 2005 status in the United States", Ann. Clin. Microbiol. Antimicrob., 5, 1-9 (2006).

3- E. Akbas, I. Berber, A. Sener and B. Hasanov, "Synthesis and antibacterial activity of 4-benzoyl-1-methyl-5-phenyl1H-pyrazole-3-carboxylic acid and derivatives", Farmaco, 60, 23-26, (2005).

4- C. G. Bonde and N. J. Gaikwad, "Synthesis and preliminary evaluation of some pyrazine containing thiazolines and thiazolidinones as antimicrobial agents",
Bioorg. Med. Chem., 12, 2151-2161 (2004).

5- M. A. Weidner-Wells, C. M. Boggs, B. D. Foleno, J. Melton, K. Bush, R. M. Goldschmidt and D. J. Hlasta, "Novel piperidinyloxy oxazolidinone antibacterial agents. Diversification of the NSubstituent", ibid., 10, 2345-2351 (2002).

6- S. Castellano, G. Stefancich, A. Chillotti and G. Poni, Synthesis and antimicrobial properties of 3-aryl-1-(1,1'-biphenyl-4-yl)2-(1H-imidazol-1-yl)propanes as 'carbaanalogues' of the Narylmethyl- N-[(1,1'biphenyl)-4-ylmethyl])-1H-imidazol-1-

amines, a new class of antifungal agents", Il Farmaco, 58, 563-568, (2003).

7- F. Malbec, R. Milcent, P. Vicart and A. M. Bure, "Synthesis of new derivatives of 4-amino-2,4-dihydro-1,2,4-triazol-3-one as potential antibacterial agents", $\boldsymbol{J}$. Heterocycl. Chem., 21, 1769-1774 (1984).

8- A. H. El-Masry, H. H. Fahmy and S. H. Ali Abdelwahed, "Synthesis and antimicrobial activity of some new benzimidazole derivatives", Molecules, 5, 1429-1438 (2000).

9- H. A. Saadeh, I. M. Mosleh, A. G. AlBakri and M. S. Mubarak, "Synthesis and antimicrobial activity of new 1,2,4triazole-3-thiol metronidazole derivatives", Monatsh. Chem., 141, 471-478 (2010).

10- U. Salgin-Gökşen, N. Gökhan-Kelekçi, O. Göktaş, Y. Köysal, E. Kiliç, S. Işik, G. Aktay and M. Ozalp, "1Acylthiosemicarbazides, 1,2,4-triazole5(4H)-thiones, 1,3,4-thiadiazoles and hydrazones containing 5-methyl-2benzoxazolinones: synthesis, analgesicanti-inflammatory and antimicrobial activities", Bioorg. Med. Chem., 15, 5738-5751, (2007).

11- S. S. Papakonstantinou-Garoufalias, O. G. Todoulou, E. C. Filippatos, A. E. Papadaki-Valiraki and A. ChytiroglouLada, "Synthesis, antifungal activity and antibacterial evaluation of some 3piperazinylmethyl-5-aryl-1H-1,2,4triazoles", Arzeim. Forsch./Drug Res., 48, 1019-102 (1998).

12- A. M. Hayallah and H. F. Heta, "Design and synthesis of some novel 1, 3, 5trisubstituted $[1,2,4]$ triazolederivatives as 
potential antibacterial agents", Bull. Pharm. Sci., Assiut University, 31, 375390 (2008).

13- K. A. Sadana, Y. Mirza, K. R. Aneja and O. Prakash, "Hypervalent iodine mediated synthesis of 1-aryl/hetryl-1,2,4triazolo[4,3-a]pyridines and 1-aryl/hetryl 5-methyl-1,2,4-triazolo[4,3-a]quinolines as antibacterial agents", Eur. J. Med. Chem., 38, 533-536, (2003).

14- D. Sahin, H. Bayark, A. Demirbas, N. Demirbas and S. Alpay Karaoglu, "Design and synthesis of new 1,2,4-triazole derivatives containing morpholine moiety as antimicrobial agents", Turk. J. Chem., 36, 411-426, (2012).

15- N. Kalyoncuoğlu, S. Rollas, D. SürAltiner, Y. Yeğenoğlu and O. Anğ, "1-[p(Benzoylamino)benzoyl]-4-substituted thiosemicarbazides: synthesis and antibact-rial and antifungal activities", Pharmazie, 47, 796-797 (1992).

16- M. D. Mullican, M. W. Wilson, D. T. Connor, C. R. Kostlan, R. D. Kostlan, D. J. Schrier and R. D. Dyer, "Design of 5(3,5-di-tert-butyl-4-hydroxyphenyl)-1,3,4thiadiazoles, -1,3,4-oxadiazoles, and -1,2, 4-triazoles as orally-active, nonulcerogenic antiinflammatory agents", J. Med. Chem., 36, 1090-1099, (1993).

17- B. Tozkoparan, N. Gokhan, G. Aktay, Y. Yesilada and M. Ertan, "6-Benzylidenethiazolo[3,2-b]-1,2,4-triazole-5(6H)-ones substituted withibuprofen: synthesis, characterization and evaluation of antiinflammatory activity", Eur. J. Med. Chem., 35, 743-750, (2000).

18- B. Shivarama Holla, B. Veerendra, M. K. Shivananda and B. Poojary, "Synthesis characterization and anticancer activity studies on some Mannich bases derived from 1,2,4-triazoles", ibid., 38, 759-767 (2003).

19- S. Khanage, P. Mohite, R. Pandhare and A. Raju, "Synthesis and pharmacological evaluation of isoxazole derivatives containing 1,2,4-triazole moiety", Marmara Pharm. J., 16, 134-140 (2012).

20- N. Demirbas, R. Ugurluoglu and A.Demirbas, "Synthesis of 3-alkyl(aryl)-4alkylidenamino-4,5-dihydro-1H-1,2,4triazol-5-ones and 3-alkyl-4-alkylamino4,5-dihydro-1H-1,2,4-triazol-5-ones as antitumor agents", Bioorg. Med. Chem., 10, 3717-3723 (2002).

21- M. Kritsanida, A. Mouroutsou, P. Marakos, N. Pouli, S. PapakonstantinoGaroufalias, C. Pannecouque, M. Witvouw and De Clercq, "Synthesis and antiviral activity evaluation of some new 6-substituted 3-(1-adamantyl)-1,2,4triazolo[3,4-b][1,3,4]thiadiazoles",

Farmaco., 57, 253-257, (2002).

22- G. Turan-Zitouni, Z. A. Kaplancikli, K. Erol and F. S. Kilic, "Synthesis and analgesic activity of some triazoles and triazolothiadiazines", ibid., 54, 218-223 (1999).

23- A. K. Ghose, V. N. Viswanadhan and J. J. Wendoloski, "A knowledge-based approach in designing combinatorial or medicinal chemistry libraries for drug discovery. 1. A qualitative and quantitative characterization of known drug databases", J. Comb. Chem., 1, 5568 (1999).

24- A. M. Hayallah, "Design and synthesis of new (SecinH3) derivatives as potential cytohesin inhibitors", Ind. J. Pharm. Sci., (2013) "Submitted article".

25- A. M. Clark, F. S. El-Feraly and W. S. Li, "Antimicrobial activity of phenolic constituents of Magnolia grandiflora L", J. Pharm. Sciences, 70, 951-952 (1981).

26- A. Felten, B. Grandry, P. H. Lagrange and I. Casin, "Evaluation of three techniques for detection of low-level methicillinresistant Staphylococcus aureus (MRSA): A disk diffusion method with cefoxitin and moxalactam, the Vitek 2 system, and the MRSA-screen latex agglutination test", J. Clin. Microbiol., 40, 2766-2771, (2002).

27- A. C. Scott, "Laboratory Control of Antimicrobial Therapy", In: J. G. Collee, J. P. Duguid, A. G. Fraser and B. P. Marmion (Eds.), Mackie \& McCartney Practical Medical Microbiology, Churchill Livingstone, Edinburgh, 1989, pp. 161181.

28- W. Hewitt, "Microbiological Assay, An Introduction to Quantitative Principles and Evaluation", (Academic Press) New York, London, 1977, pp. 17-69. 


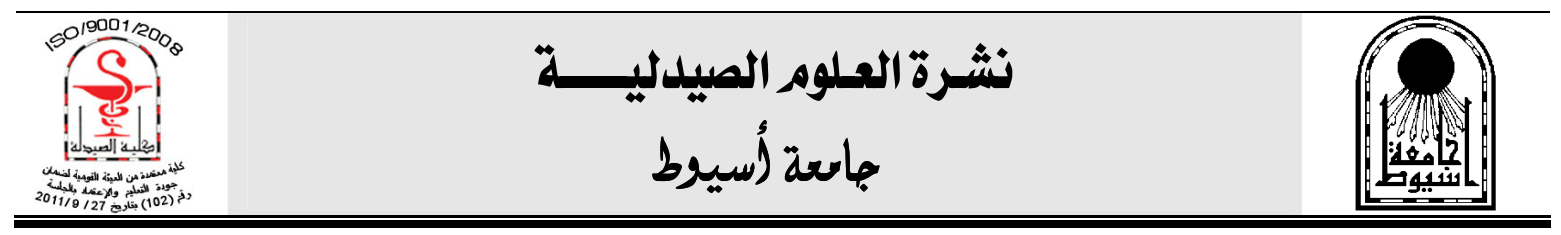

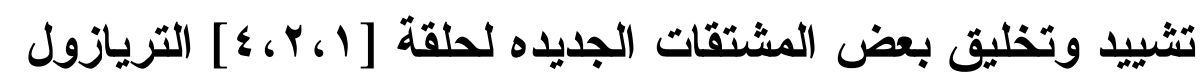
كمضادات محتملة للبكتريا

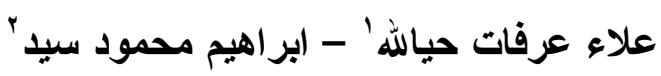

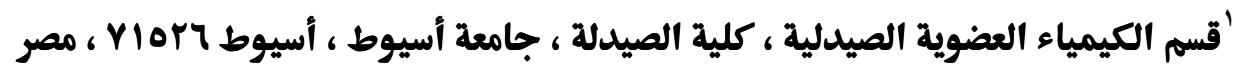

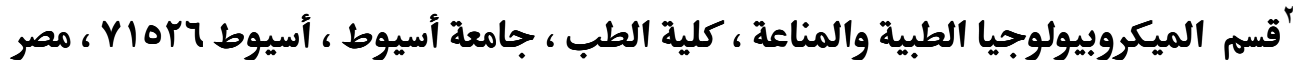

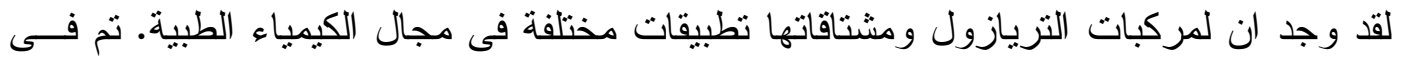

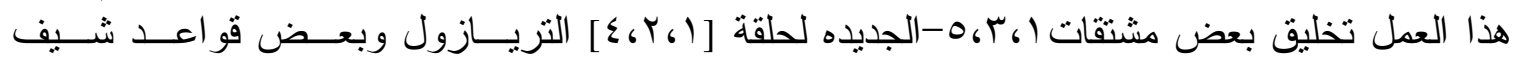

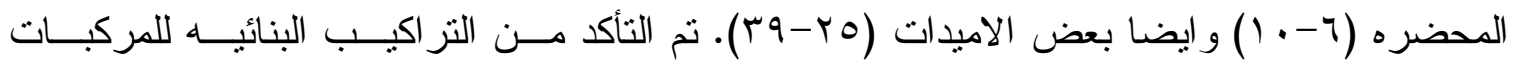
المستهدفة باستخدام طيف الاشعة تحت الحمر اء، الرنين النووى المغناطيسي، مطياف الكتلة و التحاليـلـل

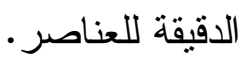

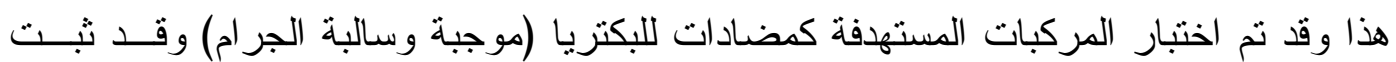

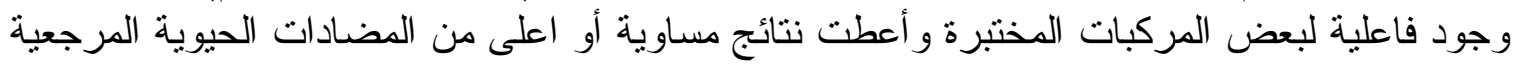

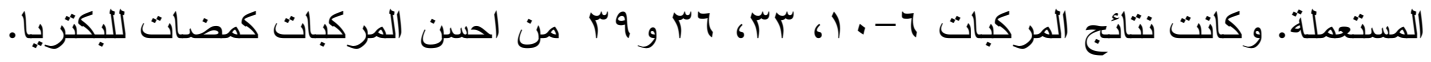

